\title{
Anatomic Evaluation of the Ophthalmic Artery in Optic Canal Decompression: A Cadaver Study of 20 Optic Canals
}

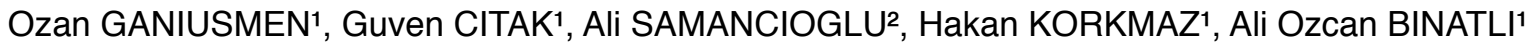 \\ ${ }^{1}$ Sifa University, Department of Neurosurgery, Izmir, Turkey \\ ${ }^{2}$ Buca Seyfi Demirsoy State Hospital, Department of Neurosurgery, Izmir, Turkey
}

\section{ABSTRACT}

AIM: A relationship was shown in this study between the optic canal and the ophthalmic artery by cadaver study. It is intended that the anatomical and histological values which we obtained can be used as a guide in surgery

MATERIAL and METHODS: A surgical anatomical evaluation was made of twenty optic canals in ten cadavers fixed in $10 \%$ formaldehyde. These were evaluated together with measurements of the ophthalmic artery and histological sections of the surrounding structure.

RESULTS: The ophthalmic artery separated from the carotid at different positions. In our material, eight (40\%) left the carotid from the upper internal part, six (30\%) from the front internal part, four (20\%) from the upper central part, and two (10\%) emerged at the end of the cavernous segment of the middle of the carotid at a steep angle. In none of the material did the ophthalmic artery originate from any other vascular structure than the carotid. Whatever position the ophthalmic artery was in within the canal on entry, it followed the outer walls of the canal and left the canal in the lower external section of the optic nerve. In the literature, work on this area has been limited to examining the anatomical values and variations in the optic canal. The results in the present study have been obtained by combining the data with surgical anatomy.

CONCLUSION: This is a method of transcranial decompression of the optic canal which is safe for the vascular structures in and around the optic canal providing certain points are kept in mind.

KEYWORDS: Ophtalmic artery, Optic canal, Decompression, Optic nerve

\section{INTRODUCTION}

A pproaches and indications for surgery on the optic canal are limited. However, this area has always attracted attention because of its position in the cranium and its relation to surrounding anatomical structures. Surgery is performed on the posterior orbit, the optic canal (OC), and the superior orbital fissure for injuries to the optic nerve which may occur as a result of trauma, for pseudotumor cerebri, angioma in the posterior orbit, neurinoma, meningioma, malignant tumors, and sphenoid wing tumors, and for ophthalmic artery (OA) aneurysms which have an extension inside the canal $(3,13,14,17,19,27)$.
On the other hand, it is necessary to have a good knowledge of the anatomical structure of this region in the approach to OA Aneurysms. The variations on the arterial system of this region are more worthy of attention than the venous system $(4,5,6,9,29)$.

In neurosurgery, the recent advances in microsurgery techniques brought by technological developments have enabled an easier and more informed approach to surgery in this area. At the same time, the relationship between the anatomical structures of this area is just as important as before. It was with this aim that cadaver studies were used to investigate the relationship between the optic nerve and the 
ophthalmic artery. The study was planned not only to collect anatomical and histological data but also to adapt the results obtained to surgical practice.

\section{MATERIAL and METHODS}

In the study, 20 OCs were examined from ten cadavers preserved in $10 \%$ formalin. The relationship between the two OCs and the OAs of each cadaver was examined.

None of the cadavers used had previously been used for work on canal pathology. All the cadavers were adults of the white race.

After anatomical measurements of the canals had been made, histological sections of the structures inside the canal were made and examined.

As the brain tissue of the cadavers had previously been removed, work could be continued without the need for first opening the skull and removing brain tissue. The study took place in the anatomy laboratory of Dokuz Eylül University Medical Faculty in Izmir, Turkey.

\section{Anatomical Evaluation}

Before measuring the bone values of the canal, measurements were made of the position of the point at which the OA left the carotid, its diameter at this point, its diameter where it entered the cranial section of the $\mathrm{OC}$, and the distance to the hole which is the entry to the OC (Table I).

In bone evaluation, the angle of the canal to the Frankfurt horizontal line (the line from the lower side of the orbit to the center of the external auditory meatus) was measured on both sides with a 180-degree protractor and noted (Figure 1). The angle formed by the canal to the sagittal plane passing through the mid-line was also measured on both sides with the same protractor and noted.
After these measurements, dissection commenced with the separation of the dural structure surrounding the opening of the cranial part of the OC from the bone structure (Figure 2). Using the surgical instruments of a fine-based Kerrison rongeur and a dissector, the space between the separated dura layer and the upper wall of the canal was penetrated. The upper wall of the canal was removed so as to expose the optic nerve to the outer and inner limits of the canal and the $\mathrm{OA}$ to maximum limits. During this procedure, it was found to be very easy to separate the dura from the bone in the cranial part of the canal in all cases. It was observed that the dura adhered more closely to the bone as the orbital part of the canal was approached. In particular, this compact structure became more evident at the orbital boundary, and dissection here became very difficult. It was found that this characteristic was important for exposing the orbital boundary of the canal. In addition, it was observed in particular that the attachment points of the ocular muscles located in the orbital part of the

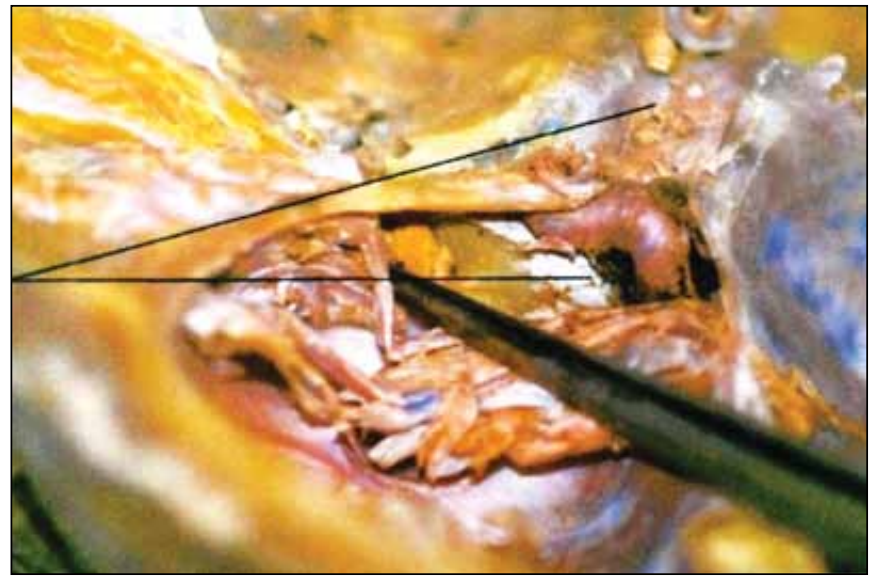

Figure 1: Frankfurt horizontal line.

Table I: Ophthalmic Artery Values

\begin{tabular}{|c|c|c|c|c|c|c|c|c|}
\hline \multirow{2}{*}{$\begin{array}{l}\text { Ophthalmic } \\
\text { artery }(\mathrm{mm})\end{array}$} & \multicolumn{2}{|c|}{ A1 } & \multicolumn{2}{|c|}{ A2 } & \multicolumn{2}{|c|}{ A3 } & \multicolumn{2}{|c|}{ A4 } \\
\hline & $\mathbf{R}$ & $\mathbf{L}$ & $\mathbf{R}$ & $\mathbf{L}$ & $\mathbf{R}$ & $\mathbf{L}$ & $\mathbf{R}$ & $\mathbf{L}$ \\
\hline Cadaver 1 & 1.8 & 1.7 & 1.6 & 1.5 & 1.5 & 1.4 & 1.2 & 1.1 \\
\hline Cadaver 2 & 1.8 & 1.8 & 1.5 & 1.6 & 1.5 & 1.4 & 2.9 & 2.7 \\
\hline Cadaver 3 & 1.7 & 1.7 & 1.3 & 1.3 & 1.3 & 1.3 & 3.4 & 3.6 \\
\hline Cadaver 4 & 1.7 & 1.6 & 1.4 & 1.3 & 1.3 & 1.2 & 3.8 & 3.9 \\
\hline Cadaver 5 & 1.7 & 1.8 & 1.5 & 1.6 & 1.4 & 1.5 & 2.1 & 2.3 \\
\hline Cadaver 6 & 1.6 & 1.6 & 1.4 & 1.3 & 1.4 & 1.4 & 2.6 & 2.9 \\
\hline Cadaver 7 & 2.0 & 2.0 & 1.9 & 1.9 & 1.7 & 1.8 & 2.1 & 2.3 \\
\hline Cadaver 8 & 2.0 & 2.0 & 2.0 & 2.1 & 2.1 & 2.0 & 3.6 & 3.5 \\
\hline Cadaver 9 & 1.9 & 1.7 & 1.7 & 1.6 & 1.6 & 1.6 & 3.1 & 3.3 \\
\hline Cadaver 10 & 1.8 & 1.7 & 1.6 & 1.5 & 1.6 & 1.5 & 3.2 & 3.4 \\
\hline
\end{tabular}

A1: Diameter around the carotid output, A2: Diameter of the optic canal cranial parts, A3: Diameter of the optic canal orbital parts, A4: Distance between the cranial part of optic canal and carotid output. 
canal started immediately after the orbital boundary of the canal, and adhered to the outer and inner limits of the dura of the canal (Figure 3).

The thickness of the canal covering was found to increase towards the orbital boundary. The characteristics of the bone structure on the outer part as far as the anterior clinoid process, which forms the inner and outer walls of the canal, and the bone structure making up the upper walls of the superior orbital fissure were noted, as well as those of the outer walls of the interior sphenoid sinus.

After the structure of the $\mathrm{OC}$ had been opened up as far as the orbital boundary, the optic nerve and the OA together with the dural sheath which had been freed in the canal were removed as a block by making a transverse cut with a No 15 scalpel.

The optimal eight optic nerves and ophthalmic arteries from the left and right sides of four cadavers were placed in $10 \%$ formaldehyde. Later, sections were taken of the prepared blocks, and the tissues were stained with hematoxylin and eosin, following routine histological procedures. After the staining process, the slides were examined under an Olympus $\mathrm{BH}-2$ light microscope; they were transferred to computer using a JVC Colour Video Camera Head Model No: TK-890E, after which the necessary parameters were measured using the UTHSCSA Image Tool for Windows Version 3.00, and histomorphometric analysis was performed.

\section{RESULTS}

\section{Anatomical Arterial Relationship}

After the OA emerges from the internal carotid artery, it enters the $\mathrm{OC}$ and passes into the orbit (Figure 3). It separates from the carotid at various different points. In our material, eight $(40 \%)$ came from the upper internal section, six $(30 \%)$ from the anterior internal section, four (20\%) from the upper middle section, and two (10\%) emerged at a steep angle from the middle of the carotid at the end of the cavernous section. In none of the material did the OA originate from any vascular structure other than the carotid.

The diameter of the $O A$ at the point where it left the carotid artery (at its origin) was measured as a mean of $1.8 \pm 0.13 \mathrm{~mm}$ $(1.6-2.0)$ on the right side and a mean of $1.76 \pm 0.14 \mathrm{~mm}$ (1.62.0) on the left side. The diameter of the OA was measured at the entry to the optic canal cranial section both with a manual caliper and in the histological sections with the aid of the computer. In the manual measurements, the mean on the right side was found to be $1.59 \pm 0.2 \mathrm{~mm}(1.3-2.0)$, and on the left side $1.57 \pm 0.2 \mathrm{~mm}(1.3-2.1)$ (Table I).

The length of the OA from where it leaves the carotid artery to where it enters the cranial section of the optic canal was measured as $2.8 \pm 0.8 \mathrm{~mm}(1.2-3.8)$ on the right side and $2.9 \pm 0.83 \mathrm{~mm}(1.1-3.9)$ on the left (Table I). After leaving the carotid, fourteen $(70 \%)$ of the OAs entered the canal through the subdural space (between the optic nerve and the dura). Four $(20 \%)$ entered the canal between the two layers of the dura, and two (10\%) entered through the extradural space and the end of the cavernous part of the carotid artery. The OA that entered the canal through the subdural space entered the intradural space after crossing a mean distance of $3.2 \mathrm{~mm}$ (2.1-4 $\mathrm{mm}$ ) between the dura and the optic nerve. Its mean

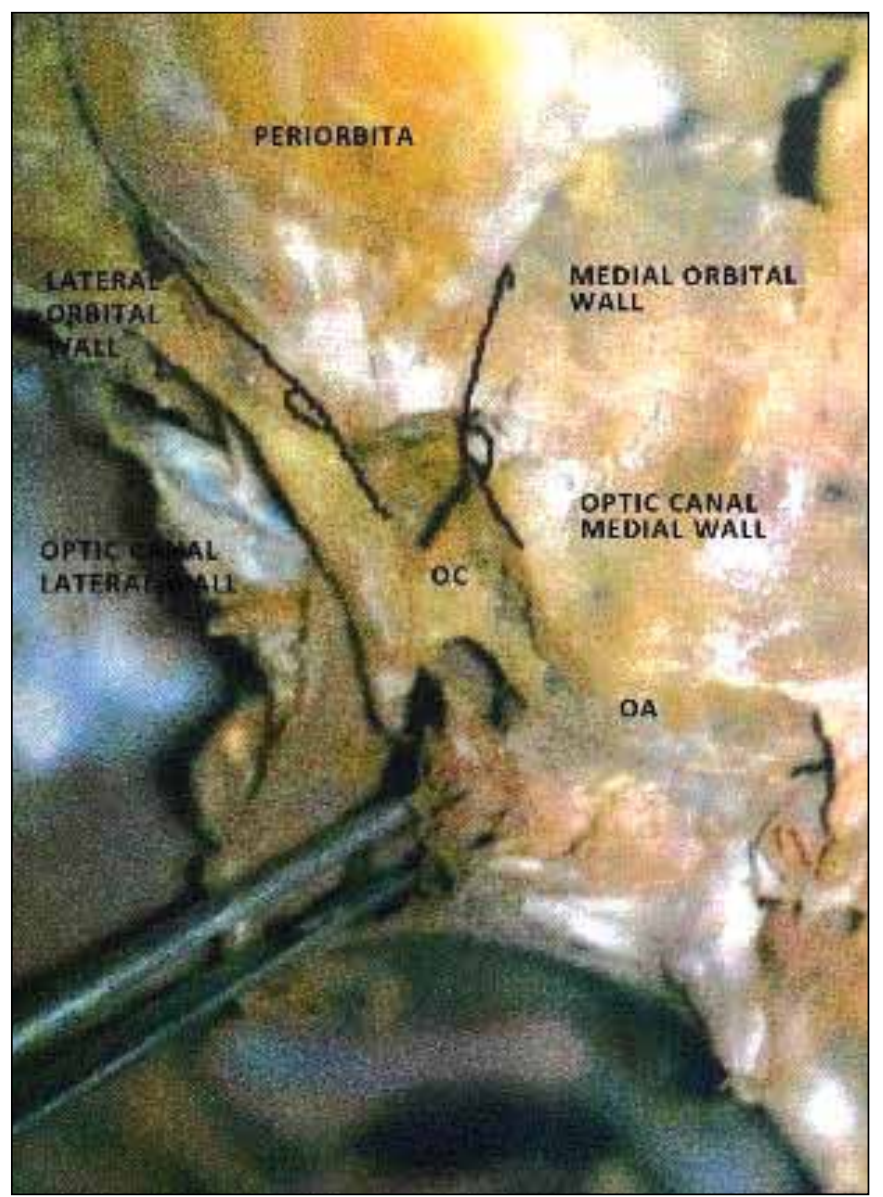

Figure 2: Optic canal measurements. OC: Optic canal, OA: Ophthalmic artery.

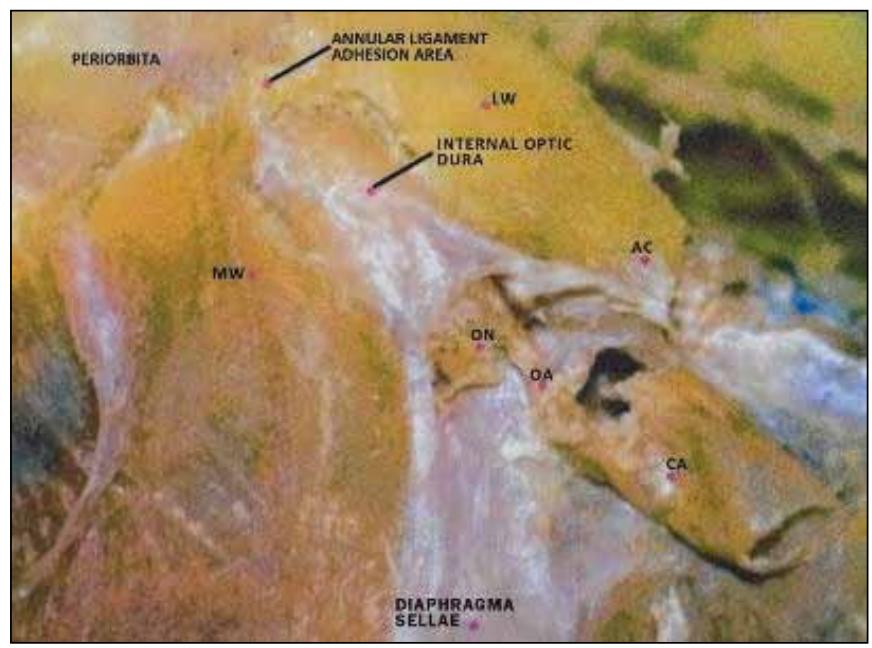

Figure 3: After optic canal decompression. MW: Medial wall, LW: Lateral wall, CA: Carotid artery, ON: Optic nerve, AC: Anterior clinoid, OA: Ophthalmic artery. 
length in this space was $2.6 \mathrm{~mm}$ (1-3.4 mm). In all materials, the OA left the optic canal between the two layers of the dura. In no case was a branch of the OA found in the canal. Examining the positions of the entry of the OA into the canal relative to the optic nerve, it was observed that in $13(65 \%)$ it entered the canal from the lower outer part of the optic nerve, in five $(25 \%)$ from the lower middle part of the nerve, and in two (10\%) from the lower inner part of the nerve. No OA was seen to enter the canal from the upper part of the nerve.

In the route of the OA inside the canal, when it was at the outer section entry of the nerve in terms of positions of entry to the canal, it passed through the canal beside the outer wall of the canal, and left the canal at the orbital space at the lower outer section of the nerve.

When the OA was at the lower section entry of the nerve or at the inner part entry, it turned outwards and left the canal orbital space at the lower outer part of the nerve. In all cases, the OA was located in the lower outer part of the nerve in the canal orbital part. In no case was the OA found to follow the upper part of the nerve in the canal orbital space. In addition, the OA was not seen to follow the inner wall of the canal and leave it from the inner part of the nerve.

The mean diameter of the OA at the orbital part of the canal was measured as $1.52 \pm 0.3 \mathrm{~mm}(1.1-2.1)$ on the right, and $1.49 \pm 0.3 \mathrm{~mm}(1.1-2.2)$ on the left.

In one case, after the right OA left the carotid, it entered the canal via its own ophthalmic groove. This was different from all the other cases.

\section{Evaluation of Histological Sections}

Measurements were made of the width and height of the parts of the ophthalmic artery and optic nerve in the histological sections (Table II).

\section{DISCUSSION}

Compression of the part of the optic nerve inside the canal can be relieved by removing the roof of the OC. Also, an incision in the covering of the optic nerve and sometimes mobilization may be of benefit in order to gain a better view in the case of paraclinoid aneurysms and some tumors $(5,8,15,22)$.

There is wide variation in the $\mathrm{OC}(9,25)$. Various anomalies can occur during fetal development. Thale et al. found keyhole anomalies in 33\% of orbits examined and 8-shaped anomalies in $2.5 \%$ (33). Magden and Kaynak found duplicate canal variation in $0.27 \%$ of the orbits which they examined
(25). In one optic canal (5\%) out of 20 in the present study, an ophthalmic foramen was found which passed through the OA by itself.

Jimenes at al. observed that the OA generally emerged from the internal carotid artery as the first large branch, and entered the orbit through the optic canal by penetrating the dura $(16,30)$. Hayreh and Dass found that the OA left the main artery by the anterior internal side in $53.6 \%$ of cases, by the upper internal side in $37.5 \%$, by the internal side in $7.1 \%$, and by the anterior upper side in $1.8 \%$ of cases $(12,23,26)$. Lang et al. reported that the origin of the artery was in the upper internal part of the siphon in $45 \%$ of cases, in the upper part of the middle section in $22 \%$, and in the laterobasal part of the carotid siphon in $20 \%(2,21)$. Govsa et al. reported that the OA was in the upper internal part of the carotid siphon in $51.8 \%$ of cases, in the central part of the upper section in $26.2 \%$, and laterobasal in $22 \%(9,20,32)$. Rhoton found that the OA often left the anterior bend of the internal carotid artery from the internal half of the upper side, immediately above the cavernous sinus $(1,7,11,29)$. In the present study also, eight OAs $(40 \%)$ left the carotid in the upper internal section, six $(30 \%)$ in the anterior internal section, four $(20 \%)$ in the upper middle section, and two (10\%) at a steep angle at the end of the cavernous section of the carotid almost in the middle of the carotid. In no case did the OA originate from any other vascular structure than the carotid. These writers emphasized that sometimes the first part of the OA was broadened in their series, and exerted pressure on the optic nerve from below, and that in these cases the nerve was thin and degenerated. In the present study no evidence of such pressure was encountered.

According to the findings of Lang and Kageyama, in $80 \%$ of cases the OA passed through the subdural space, and in $10 \%$ it emerged into the subdural space from the anterior $1 / 3$ of the OC cranial opening $(21,24,28)$. Lang and Kageyama measured the length within the dura as $3.14 \mathrm{~mm}(1-8 \mathrm{~mm})$ and its extension within the dura to the OC as $2.84 \mathrm{~mm}(0-7.3$ $\mathrm{mm}$ ). They found that in $85 \%$ of cases the artery followed the outer wall of the canal $(21,30)$. It was reported by Govsa et al. that the route of the artery had similar characteristics (9, $34)$. In the present study, 14 OAs (70\%) entered the canal via the subdural space (between the optic nerve and the dura) after leaving the carotid artery. Four OAs (20\%) entered the canal between two layers of the dura, and two (10\%) entered through the extradural space at the end of the cavernous part of the carotid. The OAs that entered the canal in the subdural space progressed for $3.2 \mathrm{~mm}(2.1-4 \mathrm{~mm})$ between the dura

Table II: Mean Values of the Results of Histological Sections

\begin{tabular}{lcc}
\hline & $\mathbf{R}$ & $\mathbf{L}$ \\
\hline Ophthalmic artery width $(\mathrm{mm})$ & $1.32(0.94-1.64)$ & $1.19(0.83-1.80)$ \\
\hline Ophthalmic artery height $(\mathrm{mm})$ & $0.76(0.23-1.23)$ & $0.77(0.48-1.14)$ \\
\hline Optic nerve width $(\mathrm{mm})$ & $4.39(3.91-5.01)$ & $4.44(3.98-4.76)$ \\
\hline Optic nerve height $(\mathrm{mm})$ & $2.81(1.84-3.55)$ & $2.48(1.65-3.02)$ \\
\hline
\end{tabular}


and the optic nerve, then entered the area within the dura. This distance was $2.6 \mathrm{~mm}$ (1-3.4 mm). In all cases, the OA left the optic canal between two layers of the dura. In no case was a branch of the OA found inside the canal.

Inside the canal, our findings showed that whatever the position of the OA at entry, it followed the outer wall of the canal and left the canal at the lower outer section of the optic nerve.

Lang and Kageyama found the normal outer diameter of the $O A$ to be $1.5 \mathrm{~mm}(1.1-1.9 \mathrm{~mm})(21)$. In a few cases a dolicomegalic ophthalmic artery was found which had an infundibular widening with an external diameter of up to 2.8 $\mathrm{mm}$ that pressed the optic nerve to the dural covering inside the OC $(21,34)$. In our material, no infundibular widening or doligomegalic arteries were found.

Chou et al. found a subdural sectional area of $1.8 \mathrm{~mm}^{2}$ $(6,9,10,18,31)$. In our materials, the optic nerve subarachnoid area in the cranial section was $4.68 \mathrm{~mm}^{2}\left(4.19-5.13 \mathrm{~mm}^{2}\right)$ on the right and $4.85 \mathrm{~mm}^{2}\left(4.08-5.86 \mathrm{~mm}^{2}\right)$ on the left, and in the sections taken of the middle part of the optic canal the optic nerve subarachnoid area was measured as $3.29 \mathrm{~mm}^{2}$ (3.08$\left.3.62 \mathrm{~mm}^{2}\right)$ on the right and $3.52 \mathrm{~mm}^{2}\left(3.25-3.89 \mathrm{~mm}^{2}\right)$ on the left, and in sections of the OC taken from the orbital part, 2.24 $\mathrm{mm}^{2}\left(1.85-2.88 \mathrm{~mm}^{2}\right)$ on the right and $1.97 \mathrm{~mm}^{2}(1.72-2.22$ $\mathrm{mm}^{2}$ ) on the left.

In the literature, studies in this area are confined to setting out the anatomical values of the $\mathrm{OC}$ and their variations. The results of the present study were obtained by a meeting of surgery and anatomy. It is felt that this surgical anatomical information may be of use in daily surgical practice, where it may serve as a guide.

In surgery, the fact that the optic canal can have more than one orientation is of critical importance. Optical channel Frankfurt horizontal plane and the sagittal plane angles proper head position and orientation can be used for surgery. In the present study, the optic canal was found to extend downwards at an angle to the Frankfurt horizontal line of $16.8 \pm 1.68$ degrees (14-19) on the right and $16.2 \pm 1.47$ degrees (14-18) on the left, and outward from the midline at an angle of $30.7 \pm 1.49$ degrees (28-32) on the right and $30.8 \pm 1.47$ degrees (28-33) on the left from the plane passing through the midline. When we take these values into consideration, the patient's head needs to be turned outwards at an angle of approximately 30 degrees and extended by 15 degrees for the canal to be brought into an upright position on the operating table. When this maneuver is known, the surgeon can arrange any desired position. Transcranial OC decompression surgery begins from the posterior opening of the optic canal. This area is in close relationship with the internal carotid artery (Figure 3). Generally, the artery is located in the lower exterior part of the canal and is far from the decompression area. However, a possible tortuosity in the carotid siphon may bring this artery closer to the decompression area. This must not be forgotten. Decompression must be carried out from the middle of the upper wall of the optic canal after opening the upper dura of the canal. This is the ideal site for safe decompression. Because the OA was not above the optic nerve in any of our cases nor was this described by any other writer, the likelihood of damaging the ophthalmic artery by opening the upper wall is low. In the present study, the length of the upper wall was measured as $8.29 \pm 1.1 \mathrm{~mm}(7.0-10.2)$ on the right and $8.35 \pm 1.12 \mathrm{~mm}(6.5-10.0)$ on the left. Taking these values into account, approximately $8-10 \mathrm{~mm}$ of the roof of the optic canal should be removed. After opening the upper wall of the optic canal, progress from the center of the canal towards the inner wall should be performed carefully. The outer wall of the sphenoid sinus, which forms the inner wall of the canal, is very thin. It is very easy to enter the sphenoid sinus during surgery if instruments are handled carelessly. The outer wall of the canal is connected to the lower wall by a very thin bone. It has been observed during canal decompression that because of these structural characteristics, the outer wall can easily be mobilized. This outer wall mobilization can damage the structures that pass though the superior orbital fissure. In cases where there is an ophthalmic foramen and the OA passes along the lower wall of the canal, compression of the OA may be caused by mobilization of the outer wall or possible damage to the lower wall. For this reason, it is of the utmost importance to use high-speed dril in decompression in order to prevent complications. The existence of an ophthalmic foramen may be important in surgery on ophthalmic segment aneurysms. In conventional cerebral angiography, a 90-degree angle between the internal carotid and the OA must suggest the possibility of an accessory ophthalmic foramen, and this must not be ignored in surgery.

\section{CONCLUSION}

The data obtained from examination and detailed measurements of the anatomical relationship between the $\mathrm{OC}$ and the $\mathrm{OA}$ are of great importance in adapting surgery and making it easier. Keeping a number of characteristics in mind provides a safe method for protecting vascular, neural and surrounding tissue in transcranial OC decompression.

\section{ACKNOWLEDGEMENTS}

The thesis work of Dr. Guven Çitak with the case number " 132020 ", is recorded in the records system of the Turkish High Education Ministry. It was permission for publication from Council of Higher Education.

\section{- REFERENCES}

1. Al-Mefty O, Fox JL, Al-Rodhan N, Dew JH: Optic nerve decompression in osteopetrosis. J Neurosurg 68(l): 80-84, 1988

2. Anderson RL, Flaharty PM: Treatment of pseudotumor cerebri by primary and secondary optic nerve sheath decompression. Am J Ophthalmol 113(5): 599-601, 1992

3. Brovman ND, Spoor TC, Ramocki JM: Optic nerve sheath decompression for pseudotumor cerebri. Arch Ophthalmol 106(10): 1378-1383, 1988 
4. Call NB: Decompression of the optic nerve in the optic canal. A transorbital approach. Ophthal Plast Reconstr Surg 2(3): 133-137, 1986

5. Chen YR, Breidahl A, Chang CN: Optic nerve decompression in fibrous dysplasia: Indications, efficacy, and safety. Plast Reconstr Surg 99(1): 22-30, 1997

6. Chou PI, Sadun AA, Lee H: Vasculature and morphometry of the optic canal and intracanalicular optic nerve. J Neuroophthalmol 15:186-190,1995

7. Chow JM, Stankrewicz JA: Powered instrumentation in orbital and optic nerve decompression. Otolaryngol Clin North Am 30(3): 467-478, 1997

8. Girard B, Lamas G, Bouzas E, Topouzis F, Soudant: J Surgical decompression of the optic nerve in intracanal injuries. Indications and results. J Fr Ophtalmol 15(2): 83-92, 1992

9. Govsa F, Erturk M, Kayalioglu G, Pinar Y, Ozer MA, Ozgur T: Neuro-arterial relations in the region of the optic canal. Surg Radio Anat 21: 329-335, 1999

10. Guyer DR, Miller NR, Long DM, Allen GS: Visual function following optic canal decompression via craniotomy. J Neurosurg 62(5): 631-638, 1985

11. Habal MB, Maniscalco JE, Rhoton AL Jr: Microsurgical anatomy of the optic canal correlates to optic nerve exposure. J Surg Res 22: 527-533, 1977

12. Hayreh SS, Dass R: The ophthalmic artery: I. Origin and intracranial and intra-canalicular course. Br J Ophtalmol 46(2):6598, 1962

13. Hupp SL, Glaser JS, Frazier-Byrne S: Optic nerve sheath decompression. Review of 17 cases. Arch Ophthalmol 105(3): 386-389, 1987

14. Hupp SL, Buckley EG, Byrne SF, Tenzel RR, Glaser JS, Schatz NS: Posttraumatic venous obstructive retinopathy associated with enlarged optic nerve sheath. Arch Ophthalmol 102(2): 254-256, 1984

15. Hwang JM, Kim IO, Wang KC: Complete visual recovery in osteopetrosis by early optic nerve decompression. Pediatr Neurosurg 33(6): 328-332, 2000

16. Jimenez CJ, Carmona A, Castellanos L: Microsurgical anatomy of the human ophthalmic artery: A mesoscopic study of its origin, course and collateral branches. Surg Radiol Anat 17: 139-143, 1995

17. Karnk PP, Maskati BT, Kirtane MV, Tonsekar K: Optic nerve decompression in head injuries. J Laryngol Otol 95(II): 11351140,1981

18. Keltner JL, Albert DM, Lubow M, Fritsch E, Davey LM: Optic nerve decompression. A clinical pathologic study. Arch Ophthalmol 95(I): 97-104, 1977
19. Kline LB, Morawetz RB, Swaid SN: Indirect injury of the optic nerve. Neurosurgery 14(6): 756-764, 1984

20. Kuppersmith RB, Alford EL, Patrinely JR, Lee AG, Parke RB, Holds JB: Combined transconjunctival / intranasal endoscopic approach to the optic canal in traumatic optic neuropathy. Laryngoscope 107(3):311-315, 1997

21. Lang J, Kageyama I: Clinical anatomy of the blood spaces and blood vessels surrounding the siphon of the internal carotid artery. Acta Anat (Basel) 139:320- 325, 1990

22. Levin LA, Joseph MP, Rizzo JF, Lessell S: Optic canal decompression in indirect optic nerve trauma. Ophthalmology 101(3): 566-569, 1994

23. Li J, Wank J, Jing X, Zhang W, Zhang X, Qiu Y: Transsphenoidal optic nerve decompression: An endoscopic anatomic study. J Craniofac Surgery 19(6):1670-1674, 2008

24. Locatelli M, Caroli M, Pluderi M, Motta F, Gaini SM, Tschabitscher M, Scarone P: Endoscopic transsphenoidal optic nerve decompression: An anatomical study. Surg Radial Anat 33(3):257-262, 2011

25. Magden O, Kaynak S: Bilateral duplication of the optic canals. Ann Anat 178:61-64, 1996

26. Miller NR: Primary tumors of the optic nerve and its sheath. Eye(Lond) 18(11): 1026-1037, 2004

27. Nevo S. Margalit NS, Lesser JB, Moche J, Sen J: Meningiomas involving the optic nerve: Technical aspects and outcomes for a series of 50 patients. Neurosurgery 53(3):523-533, 2003

28. Paridaens D, van den Bosch W: Transnasal orbital decompression in severe Graves' ophthalmopathy. Ophthalmology 108(12): 2155-2156, 2001

29. Rhoton AL Jr. The orbit. Neurosurgery 51 Suppl 4: S303-334, 2002

30. Sergott RC: Optic nerve sheath decompression: History, techniques, and indications. Int Ophthalmol Clin 31(4): 71-81, 1991

31. Spoor TC, Mathong RH: Restoration of vision after optic canal decompression. Arch Ophthalmol 104(6): 804- 806, 1986

32. Tao H, Dai P, Jiang L, Zhizhong M: Computer-aided three-dimensional reconstruction and measurement of the optic canal and intracanalicular structures. Laryngoscope 109(9):14991502, 1999

33. Thale A, Jungmann K, Paulsen F: Morphological studies of the optic canal. Orbit 21(2):131-137, 2002

34. Urolaqin SB, Kotrashetti SM, Kale TP, Balihallimath LJ: traumatic optic neuropathy after maxillofacial trauma: A review of 8 cases. J Oral Maxillofac Surg 70(5):1123-1130, 2012 